confinement. Psychonomic Science, 1967, 9, 381-382.

WEINSTOCK, S. Resistance to extinction of a running response following partial reinforcement under widely spaced trials. Journal of Comparative \& Physiological Psychology, 1954, 47, 318-323.

\title{
Induced phenylketonuria (PKU): Lack of a critical period in development
}

\begin{abstract}
ROBERT L. SCHALOCK, Hastings College, Hastings, Nebr. 68901
\end{abstract}

Thirty-six neonatal albino rats were intubed twice daily for 30 consecutive days under one of six L-phenylalanine or saline conditions to determine if there was a critical period in the development of their learning ability that was most sensitive to $L$-phenylalanine induced toxicity. Each $S$ was tested on the Maier reasoning test and on DRL:12 operant schedule beginning at 50 days of age. Results indicated that while no critical period was found, there was a larger learning deficit in Ss treated earlier and longer.

A number of recent studies dealing with the artificial induction of phenylketonuria (PKU) or hyperphenylaninemia ${ }^{2}$ in rats have suggested that there might be a critical period during which the organism is most sensitive to the effects of the excess L-phenylalanine. Goldstein (1965), for example, reports that the rate of B-Phenyllactate oxidation is slower in preweanling than in postweanling rats. Although Polidora, Cunningham, \& Waisman (1966a) were unable to detect a critical period in the development of PKU, they do report that the initial insult might occur sometime within the first 25 days of administration. Similarly, Schalock \& Klopfer (1967b) have reported an induced learning deficit that is larger in rats treated with excess L-phenylalanine from birth to 60 days, than in Ss treated from 31-60 days of age. The purpose of the present study was to determine whether, within the first 30 days of a rat's life, there is a critical period in the development of the S's leaming ability that is most sensitive to the effects of excess L-phenylalanine treatment. SUBJECTS

The Ss were 36 ( 19 male, 17 female) albino rats (Long-Evans strain) from the colony at Hastings College. The six experimental groups, comprising five litters,
NOTES

1. Based on an MA thesis done at University of British Columbia and supported in part by Grant APA-247 from the National Research Council of Canada to $R$. Wong.

2. Now at Windham College, Putney, Vt. 05346. were initially balanced with respect to sex, litter mates, and body weight.

\section{INTUBING PROCEDURE}

Within $24 \mathrm{~h}$ after birth, the Ss were divided into the following six groups: (1) Days 1-10 L-phenylalanine (L-ph), Days 11-30 saline (S); (2) 1-10 S, 11-20 L-ph, 21-30 S; (3) 1-20 L-ph, 21-30 S; (4) 1-20 S, 21-30 L-ph; (5) 1-30 L-ph; and (6) 1-30 S. Ss within each group were intubed twice daily ( 8 a.m. and 8 p.m.) with either L-phenylalanine $(3 \mathrm{~g} / \mathrm{kg}$ of a $5 \%$ L-phenylalanine solution $)^{3}$ or physiological saline $(60 \mathrm{cc} / \mathrm{kg})$. All intubation was by means of a polyethylene tube connected to a $20 \mathrm{ml}$ syringe. Weekly blood and urine samples were collected 105-150 min after intubation for serum-phenylaline ${ }^{4}$ and phenylpyruvic acid $^{5}$ determinations. A 20-day recovery period (Perez, 1965; Schalock \& Klopfer, 1967b) followed the 30-day intubation period.

APPARATUS AND

The Maier reasoning test (Maier, 1932) and a DRL (differential reinforcement of low rate of responding) 12 -sec schedule (Leaf, Carlton, \& Hess, 1965) conducted in a Gerbrands G 2110 operant conditioning unit were used to assess the S's learning ability. Half of the Ss in each group were tested first on the reasoning test and second on the DRL: 12 schedule, with the converse for the second group. All Ss were tested beginning at 50 days of age, and all were
TESTING PROCEDURES

maintained on a 23-h food-deprivation schedule during both tests.

The procedure for the reasoning test was the same as previously used (Schalock \& Klopfer, 1967b). The test employed three tables $(77 \mathrm{~cm}$ high), connected by three elevated runways $(132 \mathrm{~cm}$ long and $4 \mathrm{~cm}$ wide). Each table differed either in size, albedo, or floor texture from the other two. Animals were adapted to the apparatus by $1 / 2$-h exploratory periods on 8 successive days with no food present. On each of the next 18 days, each animal was placed on one of the tables with six food pellets. The feeding table varied from day to day in a random fashion, with the restriction that the animal was fed on each table six times in 18 days. When the pellets were partially consumed, the rat was moved to one of the other tables and permitted to run once either to the table with food or to the one without. After the first day, the erroneous response consisted in running to the table on which the animal had been fed on the previous day. Reasoning scores were the ratios of the difference in frequencies of correct and incorrect responses to the total number of responses. In addition, the amount of time spent at the choice point (a point equidistant from each of the three tables) was recorded for both correct and incorrect responses. The number of tables visited during adaptation and testing was also recorded.

The procedure for the DRL: 12 schedule involved six stages: (1) an initial training period on a FR 1:1 schedule until each $S$ was responding at least 110 times within a 30-min test period; (2) a 1:1 schedule for $10 \mathrm{~min}$ (10 reinforcements), followed by a 60 min extinction period; (3) a 30 -min $1: 1$ session during which all responses were reinforced; (4) a final 1:1 schedule involving 25 rewards; (5) the six DRL: 12 sessions $(50$ reinforcements per session); and (6) a final 45-min extinction period. During the six consecutive-day DRL:12 sessions, only those responses that occurred after a 12-sec period of not responding were reinforced. The S's score was the number of responses emitted to acquire the 50 reinforcements.

\section{RESULTS}

Biochemically, the Ss were phenylketonuric while receiving the excess

Table 1

Reasoning Scores Obtained on Maier Reasoning Test and Time Spent at Choice Point ( $N=6$ per group)

\begin{tabular}{cccc} 
& $\begin{array}{c}\text { Mean } \\
\text { Reasoning } \\
\text { Score }\end{array}$ & & \multicolumn{2}{c}{\begin{tabular}{c} 
Average Time (in sec) Spent at Choice Point \\
\cline { 3 - 4 }
\end{tabular}} & $\begin{array}{c}\text { On Correct } \\
\text { Response Trials }\end{array}$ & $\begin{array}{c}\text { On Incorrect } \\
\text { Response Trials }\end{array}$ \\
\hline $1-10$ L ph & $.11 \pm .07$ & 2.2 & 3.1 \\
1.20 L ph & $.04 \pm .10$ & 2.7 & 3.3 \\
$1-30$ L ph & $.02 \pm .13$ & 3.1 & 2.5 \\
$11-20$ L ph & $.04 \pm .09$ & 2.1 & 2.4 \\
$21-30$ L ph & $.20 \pm .12$ & 2.3 & 3.0 \\
$1-30$ Saline & $.55 \pm .08$ & 1.3 & 2.5 \\
\hline
\end{tabular}


Table 2

Average Scores Emitted During Acquisition and Extinction of a DRL:12 Operant Schedule $(N=6$ per group)

\begin{tabular}{|c|c|c|c|c|c|}
\hline Group & $\begin{array}{c}\text { Initial } \\
\text { Training } \\
\end{array}$ & $\begin{array}{c}\text { Extinction } \\
(60 \mathrm{~min})\end{array}$ & $\begin{array}{c}\text { FR } 1: 1 \\
(30 \mathrm{~min})\end{array}$ & $\begin{array}{c}\text { DRL: } 12^{*} \\
\text { (6 sessions) }\end{array}$ & $\begin{array}{c}\text { Extinction } \\
\text { (45 min) }\end{array}$ \\
\hline $\begin{array}{r}1-10 \mathrm{~L} \text { ph } \\
1-20 \mathrm{~L} \text { ph } \\
1-30 \mathrm{~L} \text { ph } \\
11-20 \mathrm{~L} \text { ph } \\
21-30 \mathrm{~L} \text { ph } \\
1-30 \text { Saline }\end{array}$ & $\begin{array}{l}183 \\
173 \\
167 \\
192 \\
188 \\
243\end{array}$ & $\begin{array}{l}87 \\
51 \\
78 \\
61 \\
90 \\
61 \\
\end{array}$ & $\begin{array}{l}178 \\
189 \\
196 \\
204 \\
188 \\
176 \\
\end{array}$ & $\begin{array}{l}2470 \\
2178 \\
2885 \\
2307 \\
2160 \\
1513 \\
\end{array}$ & $\begin{array}{l}205 \\
164 \\
170 \\
174 \\
194 \\
146\end{array}$ \\
\hline
\end{tabular}

* Means based on total responses per $S$ for six DRL:12 sessions

L-phenylalanine. Average phenylpyruvic acid level for all $\hat{S s}$, while receiving the excess amino acid, was $85 \mathrm{mg}$ per $100 \mathrm{ml}$ of urine; average serum phenylalanine level was $20 \mathrm{mg}$ per $100 \mathrm{ml}$ of serum. These values are similar to those previously reported (Schalock \& Klopfer, 1967a, b; Waisman \& Harlow, 1965). No L-phenylalanine Ss were excreting elevated levels of phenylpyruvic acid at the time of testing. Saline controls Ss (1.30 S) were slightly heavier at the end of the 30-day intubation period (1-10 $\mathrm{L}-\mathrm{ph}=79 \mathrm{~g} ; \quad 1-20 \quad \mathrm{~L}-\mathrm{ph}=70 \mathrm{~g} ; \quad 1-30$ $\mathrm{L}-\mathrm{ph}=69 \mathrm{~g} ; \quad 11-20 \quad \mathrm{~L}-\mathrm{ph}=76 \mathrm{~g} ; \quad 21-30$ $\mathrm{L} \cdot \mathrm{ph}=77 \mathrm{~g} ;$ and $1-30$ saline $=87 \mathrm{~g}$ ). Weights did not differ, however, at the beginning of testing $(150,147,150,148$, 152 , and $160 \mathrm{~g}$, respectively). The amount of solution injected per group was: $1-30 \mathrm{~L}-\mathrm{ph}, 41.9 \mathrm{cc} ; 21-30,28.0 \mathrm{cc} ; 1-20$, $15.5 \mathrm{cc} ; 11-20,14.4 \mathrm{cc}$; and 1-10,6.3 cc.

Table 1 presents the average reasoning scores and the average time spent at the choice point for the six groups. Significant differences were found in reasoning scores among all six groups $(F=4.50$, df $=5 / 30$, $p<.005)$, but not among the five L-phenylalanine groups $(F<1)$. The 21-30-day L-ph group did not differ significantly from the control $(t=2.69$, $\mathrm{df}=10, \quad \mathrm{p}<.05)$. Control Ss spent significantly less time at the choice point (CP) on correct response trials $(F=4.78$, $\mathrm{df}=5 / 30, \quad \mathrm{p}<.005) ;$ however, closer analysis indicated that significant differences were found only between saline and $1-20 \mathrm{~L}$-ph $(\mathrm{t}=3.60, \mathrm{df}=10, \mathrm{p}<.01)$ and saline/1-30 L-ph $(\mathrm{t}=4.58, \mathrm{df}=10$, $p<.01)$. There were no significant differences among the L-phenylalanine groups on $\mathrm{CP}$ times either on correct responses $(F=2.01, \mathrm{df}=4 / 25, \mathrm{p}>.10)$ or among any of the six groups on incorrect responses $(F<1)$, number of tables visited during the Days 1-8 exploratory period $(\mathrm{F}=1.50, \mathrm{df}=5 / 30, \mathrm{p}>.20)$, during the 18-day testing period $(F<1)$, or time spent on the tables during exploration and testing $(F=1.27, \mathrm{df}=5 / 30, \mathrm{p}>.20)$.

Table 2 presents the average scores for the six stages of the DRL: 12 schedule. The six groups did not differ significantly on the initial training $(F=2.58, d f=5 / 30$, $p<.05)$, the first extinction $(F=2.48$, $\mathrm{df}=5 / 30, \mathrm{p}>.05)$, relearning $(\mathrm{F}<1)$, or final extinction $(F=1.26, d f=5 / 30$, $\mathrm{p}>.20$ ). During the six DRL: 12 sessions, the control group emitted significantly fewer responses $(F=4.57, \quad \mathrm{df}=5 / 30$, $\mathrm{p}<.005$ ). The five $\mathrm{L}$-phenylalarine groups did not differ significantly on DRL:12 performance $(F=1.72, d f=4 / 25, p>.10)$, and again there were no significant differences between the control and 21-30 L-ph group $(\mathrm{t}=2.03, \mathrm{df}=10, \mathrm{p}>.10)$.

\section{DISCUSSION}

The major result of the study was that although L-phenylalanine fed animals were deficient on the complex learning measures employed, no critical period was found in the development of this deficiency. The implication from the present data is that the deficit was related either to earlier insult or to the duration of treatment. Three results suggest this: First, even though the 1.10 L-ph group received little L-phenylalanine, their deficit was as large as the other L-ph groups; second, the 21-30 day L-ph Ss did not differ from the control group on either the reasoning test or DRL: 12 schedule, even though they received the second largest amount of L-phenylalanine; and third, the only significant differences at the choice point were between control Ss and the 1-20 and 1-30 day L-ph groups.

Dosage, however, was also a confounding variable. Polidora et al (1966a), for example, maintain that the learning deficit found in their postweanling PKU Ss was related to dosage, and once the initial insult occurs there is no cumulative or additional effects. The present study partially supports this latter statement. Work is presently under way to unravel the interactive effects of age, dosage, and duration.

Apart from an inferred "intellective deficit," there is little evidence as to why the L-phenylalanine Ss did worse on the complex learning measures. Consistent with previous studies (Leaf et al, 1965 ; Schalock \& Klopfer, 1967b), PKU Ss did as well as normal $S s$ on the simple acquisition and exinction tasks. Similarly, there were no differences among the groups in either exploratory patterns, in the number of tables visited, or in time spent on the tables during exploration and testing. One explanation for the complex learning deficit comes from the present and previous studies. Earlier work (Schalock \& Klopfer, 1967a, b) indicated that experimental L-phenylalanine Ss are less able to form new associations and to combine disparate experiences. This, in addition to their slower responding at the choice point during the present study, suggests that the L-phenylalanine Ss might integrate and respond more slowly to stimuli than normals.

\section{REFERENCES}

GOLDSTEIN, F. B. Phenylketonuria: Limit in capacity of preweanling rats to oxidize B-phenyllactate and other a-Hydroxy acids. Science, 1965, 150, 1042-1043.

LEAF, R. C., CARLTON, P. L., \& HESS, S. M. Behavior deficit in the rat induced by feeding phenylalanine. Nature, 1965, 208, 1021-1022.

MAIER,N.R.F. The effect of cerebral destruction on reasoning and learning in rats. Journal of Comparative Neurology, 1932, 54, 45-75.

PEREZ, V. J. Phenylketonuria or phenylpyruvia oligophrenia in the rat: Behavioral and biochemical correlates. Journal of Mental Deficiency Research, 1965,9,170-182.

POLIDORA, V. J. Behavioral effects of 'phenylketonuria' in rats. Proceedings of the National Academy of Science, 1967, 57, 102-106.

POLIDORA, V. J., CUNNINGHAM, R. F., \& WAISMAN, H. A. Dosage parameters of a behavioral deficit associated with phenylketonuria in rats. Journal of Comparative \& Physiological Psychology, 1966a, 61, 436-441.

POLIDORA, V. J., CUNNINGHAM, R. F., \& WAISMAN, H. A. Phenylketonuria in rats: Reversibility of behavioral deficit. Science, 1966b, 151, 219-221.

SCHALOCK, R. L. An experimental evaluation of phenylketonuria and phenylpyruvic oligophrenia. Paper presented at the meeting of the Western Psychological Association, San Francisco, May 1967.

SCHALOCK, R. L., \& KLOPFER, F. D. Induced phenylketonuria in rats: Behavioral effects. Journal of Mental Deficiency Research, 1967a, 11, 282-287.

SCHALOCK, R. L., \& KLOPFER, F. D. Phenylketonuria: Enduring behavioral deficits in phenylketonuric rats. Science, $1967 \mathrm{~b}, 155$, 1033-1035.

WAISMAN, H. A., \& HARLOW, H. F. Experimental phenylketonuria in infant monkeys. Science, 1965, 147, 685-695. NOTES

1. The author thanks Arthur Hixson, Division of Research, Fort Steilacoom, Wash., for conducting the pilot study preceding the present study, and Rodney Peters, Hastings College, for conducting the present study.

2. H. A. Waisman. Personal correspondnece, 1968.

3. The author thanks Sandoz Pharmaceuticals and Ames Company, Inc., for the L-phenylalanine, Phenistix, and Pheniplates.

4. Pheniplate PKU Assay kit, Ames Company (Division of Miles Laboratories), Elkhart, Ind. 46514.

5. Phenistix reagent strips, Ames Company (Division of Miles Laboratories), Elkhart, Ind., 46514. 